\title{
COMPARISON OF METHODS FOR PREDICTING THE INFLUENCE OF RESIDUAL STRESSES ON BRITTLE FRACTURE
}

\author{
Ali Mirzaee Sisan \\ TWI Ltd, \\ Cambridge, UK
}

\author{
Saeid Hadidi-Moud \\ Bristol University, \\ Bristol, UK
}

\author{
David John Smith \\ Bristol University, \\ Bristol, UK
}

\begin{abstract}
This paper compares different methods for predicting the influence of residual stresses on brittle fracture. Comparison is made between fracture predictions of a local statistical approach based on the Beremin type model, with those of a well-known fracture assessment procedures, BS7910 and R6 that uses a failure assessment diagram (FAD). The results from both methods are discussed and compared. The study focuses on the behaviour of a ferritic steel pipe containing a partthrough circumferential thumb-nail crack on the outer surface of the vessel.
\end{abstract}

\section{INTRODUCTION}

One critical issue in the structural integrity assessment to be addressed is to characterise the influence of initial residual stresses on fracture. Predicting the effect of residual stresses is more important when the structure is likely to fail by brittle fracture. Tensile residual stresses may combine with in-service loads to promote failure.

Determination of fracture parameters in residual stress fields has received great interest in recent years [1]. Local statistical approaches to predicting cleavage fracture toughness, mostly based on the Weibull distributions, have been developed [2-6]. Recently, a local stress based approach to fracture, developed by Hadidi-Moud et al [5] was applied to predict cleavage fracture probability in ferritic steels A533B and A508. The experimental data used for validation of the local approach were produced from standard laboratory test specimens [5].
Predictions obtained by application of the local approach for situations where the specimens were subjected to warm prestressing, WPS, prior to fracture loading at low temperature, exhibited very good agreement with the experimental data [5]. A significant feature of the developed model was the use of the same set of statistical parameters for the warm pre-stressed specimens as for the as received ones (i.e. with no prior load history) [5]. This was justified based on the fact that the model predictions were governed by the stresses within the plastic zone formed in the crack tip region. Since the prior loading history, WPS in this case, will change the stresses at a specified load when compared with the stresses corresponding to similar load in the as received conditions, it is anticipated that the stress field would automatically contain the prior load history effect and thus will account for its contribution to fracture. The concept was then further examined by application of the local approach to different types of load history. Initial residual stress fields were generated by either local compression, or in plane compression $[7,8]$ in laboratory sized samples. Application of the local approach to predict brittle fracture had consistent trends with experiments, although for some load history and or geometry configurations predictions did not completely accommodate the experimental findings [8]. The differences were addressed in the light of possible affecting parameters such as the micro-structural changes, crack tip blunting and change of constraint due to localised plastic deformation $[7,8$, 9]. This paper further explores the implication of local approach in predicting the brittle fracture in presence of an 
initial tensile residual stress filed in an industry sized sample, i.e. a pipe. Implication of local approach [5] provides more information about the interaction of residual stresses and applied load at the crack tip whereas assessment codes $[10,11]$ consider the residual stress effect more globally (as a secondary stress intensity factor).

This study focuses on the behaviour of a pipe made of A533B ferritic steel that contains a part-through circumferential thumb-nail crack on its outer surface. The pipe is subjected to an initial residual stress field through its thickness.

Finite element models of the pipe were produced in ABAQUS/CAE [12] and the initial stress field introduced as an initial condition for subsequent low temperature loading to fracture. The results from the FE model analysis were then used in the local approach to predict failure probability distribution. A local stress-based statistical approach to predicting cleavage fracture was considered by adopting a three parameter Weibull distribution. The Weibull parameters were determined from experimental results from fully constrained laboratory testpieces [5].

Assessment codes such as BS7910 [10] and R6 [11] provide the critical (failure) point in the as-received conditions (AR), and with initial residual stress in the pipe based on FAD analysis. Crackwise software [13], automated of BS7910 standard [10] and R-code software [14], based on R6 code [11] were used to predict the critical condition for the pipe. Both BS7910 [10] and R6 [11] use the same principles of FAD analysis. Two approaches were followed to include the initial residual stress in the assessment, (i) Linearisation of the initial residual stress field and subsequently converting the stresses into membrane and bending stresses based on recommendation in BS7910 [10] and (ii) using R-code [14] facilities to predicting an equivalent of secondary stress intensity factor using weight function method [14].

Local approach and FAD analysis are discussed, and the results compared in the following sections.

\section{LOCAL APPROACH PREDICTION}

A local stress based approach to predict fracture, developed by Hadidi-Moud et al [5] was used in this study. This approach was based on Beremin model [15]. Beremin model describes the scatter in data in the lower transition region of ferritic steels [15]. In the local approach for brittle fracture, it is assumed that the material can be divided into many small volumes linked together like a chain. Failure of whole bulk of material commences when the weakest link breaks. The probability of failure in a modified Beremin model [15] including a threshold stress, $\sigma_{\min }$ is given by:

$$
P_{f}=1-\exp \left[-\left(\frac{\sigma_{w}-\sigma_{\min }}{\sigma_{u}-\sigma_{\min }}\right)^{m}\right]
$$

In the original Beremin model the threshold stress was not considered. The Weibull stress $\sigma_{\mathrm{w}}$ is
$\sigma_{w}=\left[\frac{1}{V_{0}} \int_{V_{p}} \sigma_{1}^{m} d V\right]^{1 / m}$

The Weibull stress determines unstable cleavage failure [15]. It depends highly on shape parameter, $m$. It is also a function of maximum principal stress, $\sigma_{1}$ over the plastic zone around the crack tip. $\sigma_{\mathrm{u}}$ is a scale parameter that equals to $\sigma_{\mathrm{w}}$ at $63.2 \%$ failure probability if $\sigma_{\min }=0$.

In the local approach concept, calibration of Weibull parameters and their dependency on temperature and constraint is an open issue $[9,16]$. The Weibull parameters are defined by calibrating the parameters to experimental data. While Beremin [15] calibrated the parameters to round notched bar data, Minami et al [17] suggested using fracture toughness results. Gao et al [18] calibrated the Weibull parameters to two different levels of constraint in cracked specimens and proposed a scheme to calibrate three parameters $m, \sigma_{\mathrm{u}}, \sigma_{\min }$ for a material. Hadidi-Moud et al [5] showed the differences in Weibull parameters calibrated to round notched bar specimens and cracked specimens. Wiesner and Goldthorpe [19] indicated differences between the parameters when determined from different specimen shapes. Milella and Bonora [20] demonstrated the high sensitivity of shape parameter, $m$ to different levels of triaxiality. Petti and Dodds [21] suggested that $\sigma_{\mathrm{u}}$ would provide the temperature dependence of the Weibull stress parameters, $\sigma_{u}$ would increase significantly with temperature whereas the shape parameter, $m$, remains (relatively) invariant of temperature over some part of the ductile to brittle transition region. They used the toughnesstemperature distribution values defined by the Master Curve [22] to estimate the temperature dependence of $\sigma_{\mathrm{u}}$.

In this study the calibrated Weibull parameters from previous study [5] were used, see Figure1.

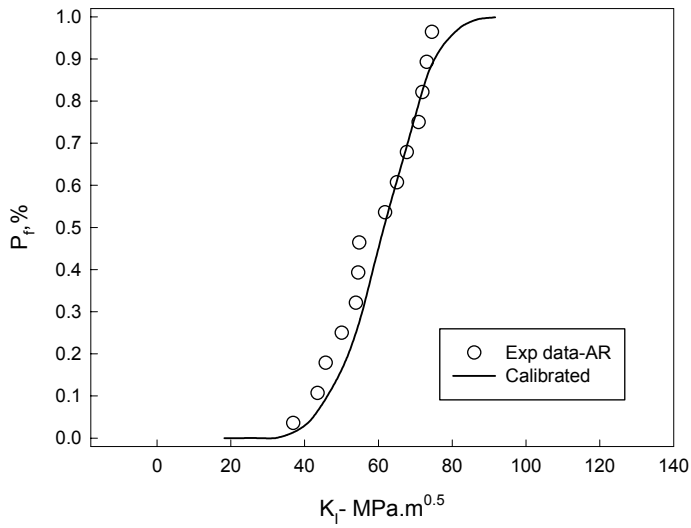

Figure 1: Calibration of Weibull parameter to AR data of $\mathrm{C}(\mathrm{T})$ and SENB specimens for A533B material at $-170^{\circ} \mathrm{C}[5]$.

The parameters were calibrated to experimental data obtained from highly constrained specimens, $\mathrm{C}(\mathrm{T})$ and SENB of A533B material at $-170^{\circ} \mathrm{C}$ in the as-received conditions [5]. 
The calibrated parameters were then used to predict the fracture behaviour of a pipe subjected to an initial residual stress field. It was assumed that the same set of Weibull parameters could be used for one material with and without residual stress field. This approach is based on FE analyses. In the following section details of FE analysis of pipe are discussed.

\section{FE SIMULATIONS}

The FE model used in this study is a $432 \mathrm{~mm}$ diameter cylindrical vessel with a thumb-nail shape part through circumferential (in the hoop direction) crack on the outer surface, $50 \mathrm{~mm}$ long and $5 \mathrm{~mm}$ through the $19.6 \mathrm{~mm}$ thick wall at its deepest point as shown in Fig 2.

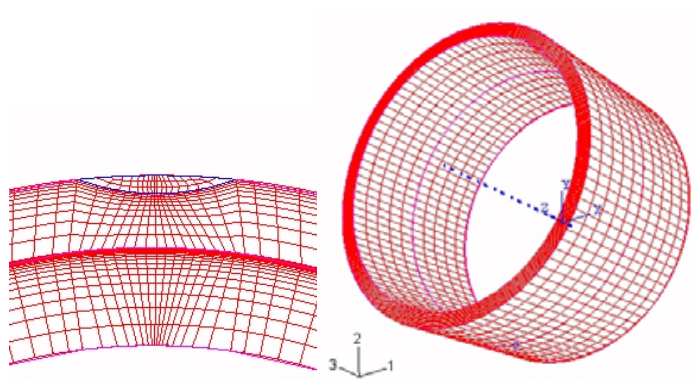

Figure 2: Geometry and crack details for the finite element model

The pipe dimensions were adapted from a previous work by Bouchard and Bradford [23] that had been used for validation of RS fields in welds. Due to symmetry conditions, with the plane of symmetry in the crack plane normal to the pipe axis, only half pipe FE models were produced in ABAQUS/CAE and used in the corresponding analyses. The whole pipe was modelled for use with general loading schemes where analyses involved introducing residual stress field as initial conditions. In the whole model the partial circumferential crack was introduced artificially by the addition of new nodes at the coordinates coincident with the nodes representing the crack face and assigning those nodes to elements on one side of the crack. For the half model the crack was identified by assigning boundary conditions to the remaining ligament at the crack plane, the plane of symmetry. The material used in this study is A533B ferritic steel for which material models at room and low $\left(-170^{\circ} \mathrm{C}\right)$ temperature were available from previous research [5].

The FE simulations were conducted in two stages. Firstly the as-received (AR) condition was assumed in the analysis. In the next stage, an initial axial residual stress (RS) field was introduced and the local approach was used to predict fracture probability in presence of initial stresses. The latter was named as initial stress-cool-fracture (ISCF). Figure 3 shows the distribution of residual stress in an un-cracked pipe and the redistribution following the introduction of the crack.

The introduction of residual stresses as initial boundary condition took place at room temperature, whereas the material was then cooled to $-170^{\circ} \mathrm{C}$ before final loading to fracture. The initial analysis was used to identify the appropriate node/element sets at the crack front area in order to obtain the stress data files containing the crack front plastic zone for use in the local approach to cleavage fracture [5]. Thus stress and plastic strain data from ABAQUS results were only extracted over the region required and were stored in a data file for use with the failure prediction model. Throughout the loadcontrolled analyses an appropriate amplitude function was used to control the load application scheme.

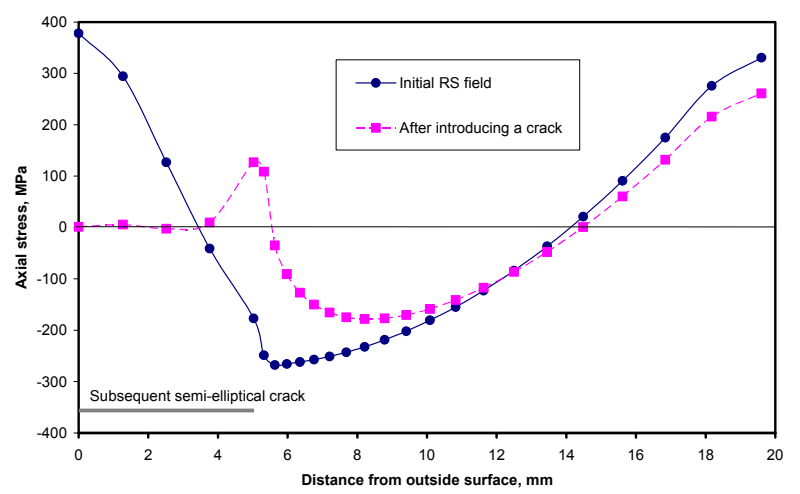

Figure 3: Initial residual stress filed

The model used for calculation of probability from Weibull stresses is given by equation (1) and Weibull stress for each increment was calculated by integrating maximum principal stress within the crack tip plastic zone, equation (2).

The failure probability distributions were plotted against stress intensity factors, SIF. The prediction of probability of failure for AR and ISCF are shown in Figure 4.

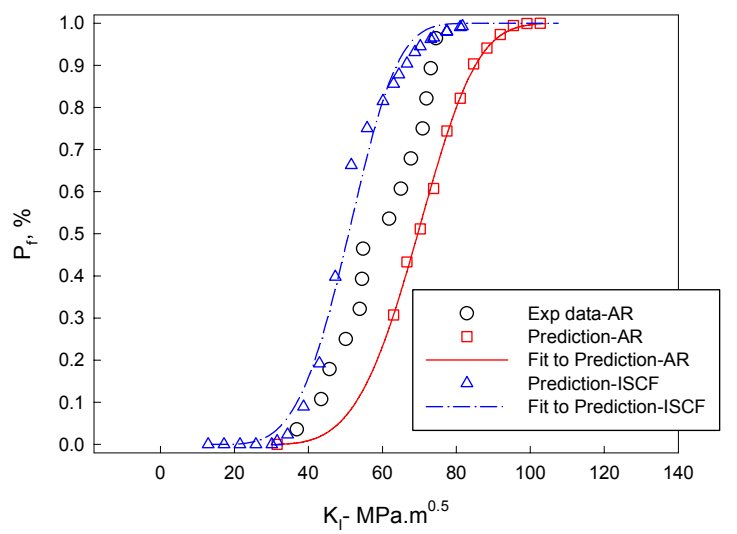

Figure 4: Prediction of probability of failure for AR and ISCF conditions of a pipe, $\mathrm{A} 533 \mathrm{~B}$ material at $-170^{\circ} \mathrm{C}$.

The local approach predictions for fracture in the cylinder used the same Weibull parameters calibrated to the SENB and $\mathrm{C}(\mathrm{T})$ specimen test data in the as-received conditions of the same material at the same temperature in previous research, see 
Figure 1 [5]. The stress intensity factors (SIF) for the applied primary loads in FE analysis of pipe were calculated based on the solution given in BS7910 [10]. There is very slight difference between SIF solution using BS7910 [10] and R6 code [11] for this geometry and load condition [24].

Also shown in Figures 2 and 4 is the experimental data from previous study where the Weibull parameters were calibrated. The experimental data were ranked and the distribution of experimental data followed equation (3) as suggested by [25]:

$P_{f}=\frac{i-0.5}{N}$

where $N$ is the total number of specimens tested and $i$ is the order number.

Figure 4 shows:

- Probability of failure distribution of apparent toughness (SIF) for the highly constraint specimens and pipe are different. This can be due to differences of constraint between the actual experimental data (highly constraint specimens) and the pipe geometry.

- The effect of initial residual stress field is about $28 \%$ reduction in apparent fracture toughness (SIF) at 50\% probability of failure.

\section{ASSESSMENT CODE PREDICTION}

Assessment codes such as BS7910 [10] and R6 [11] assess proximity to failure in a structure using two parameters, $\mathrm{K}_{\mathrm{r}}$ and $\mathrm{L}_{\mathrm{r}} . \mathrm{K}_{\mathrm{r}}$ is a measure of proximity to fracture and $\mathrm{L}_{\mathrm{r}}$ is a measure of proximity to plastic collapse. For primary load alone, $\mathrm{K}_{\mathrm{r}}$ and $\mathrm{L}_{\mathrm{r}}$ are defined by [10]:

$K_{r}=\frac{K_{l}^{p}}{K_{\text {mat }}}$

$L_{r}=\frac{\sigma_{r e f}}{\sigma_{y}}$

where $K_{I}^{p}$ is the linear elastic stress intensity factor due to the applied primary loads, $K_{\text {mat }}$ is the material fracture toughness, and $\sigma_{r e f}$ is the reference stress corresponding to the plastic limit load of the structure. Failure is predicted to occur when assessment points are on or outside the failure assessment line, also defined by [10]:

$K_{r}=\left(1-0.14 L_{r}^{2}\right)\left\{0.3+0.7 \exp \left(-0.65 L_{r}^{6}\right)\right\}$
The failure assessment line given in equation (6) has a cutoff point identified by $\mathrm{L}_{\mathrm{r}}{ }^{\mathrm{max}}$ which depends on the $0.2 \%$ proof stress, $\sigma_{v}$, and ultimate strength, $\sigma_{u}$, and is defined as [10]:

$L_{r}^{\max }=\left(\frac{\sigma_{y}+\sigma_{u}}{2 \sigma_{y}}\right)$

Under combined primary and secondary loads, $\mathrm{K}_{\mathrm{r}}$ is calculated from:

$K_{r}=\frac{K_{I}^{p}}{K_{\text {mat }}}+\frac{K_{I}^{s}}{K_{\text {mat }}}+\rho$

where $K_{I}^{s}$ is the elastic stress intensity factor due to the secondary loads, and $\rho$ is a factor covering interactions. There are different approaches to include this factor $[10,11]$. In this study the simplified procedure of $\rho$ factor was used $[10,11]$.

Primary loads in equations 4 and 8 were considered as a variable membrane axial stress. The secondary loads to be considered in the assessment were those shown in Figure 3. The stresses of un-cracked structure could be linearised and decomposed into membrane and bending stresses [10]. The other option would be to use a weight function method to calculate the equivalent stress intensity factor for this distribution [14].

Three cases were considered, and $K_{r}$ and $L_{r}$ were determined using Crackwise [13] and R-code [14], and plotted on the failure assessment diagram, shown in Figure 5. The three cases were:

Case 1: pipe in the as-received condition,

Case2: pipe with an initial residual stress field in which the residual stresses were linearised and membrane and bending stresses were applied as secondary loads [10],

Case3: pipe with an initial residual stress field in which weight function method was used for determination of secondary load from the residual stress field [14],

Equations (4) and (5) were used for case 1 and Equations (5) and (8) for cases 2 and 3. $K_{\text {mat }}$ was taken to be the average elastic stress intensity factor of the available experimental data from previous study at $-170^{\circ} \mathrm{C}$, i.e. $58 \mathrm{MPa}^{0.5}$. Both Crackwise and R-code were used for cases 1 and 2 whereas for case3, only R-code [14] was used.

The FAD curve concept, here, was used as 'failure prediction' rather than 'failure avoidance' mode. The intersection of assessment lines with FAD curve were taken as critical (failure) points. Therefore, for each case of 1, 2 and 3 there was one critical $\mathrm{L}_{\mathrm{r}}$. The effect of residual stress can be quantified by comparing $\mathrm{L}_{\mathrm{r}}$ values 


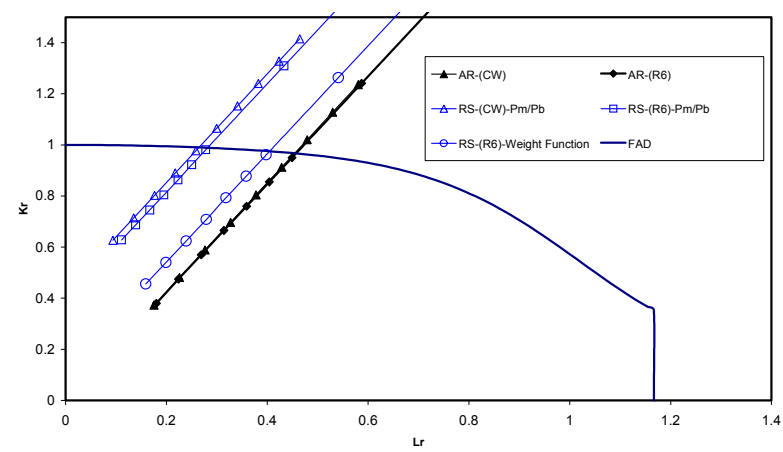

Figure 5: FAD diagram of $\mathrm{A} 533 \mathrm{~B}$ at $-170^{\circ} \mathrm{C}$

Figure 5 shows:

- Crackwise [13] and R-code [14] give identical results for case 1 where the critical $\mathrm{L}_{\mathrm{r}}=0.45$.

- There is slight difference (3\%) between Crackwise and Rcode for case2. However, both show the critical $\mathrm{L}_{\mathrm{r}}$ at about 0.27 , i.e. almost $37 \%$ of reduction in critical $L_{r}$ values.

- For case 3, the critical $\mathrm{L}_{\mathrm{r}}$, calculated by R-code is 0.4 . It means a reduction of only $11 \%$ in $L_{r}$ values.

\section{CONCLUDING REMARKS}

Previously, different residual stress fields were introduced in the conventional laboratory sized sample and the local stress approach based on Beremin model was used to predict the probability of failure. Failure predictions were promising especially with regard to the validation of calibrated Weibull parameters for various configurations of geometry and crack for the same material. It was demonstrated that the local approach could predict the effect of warm pre-stressing (compressive residual stress ahead of crack tip) very well. However, the local approach over predicted the effect of local and in plane compression (tensile residual stress ahead of crack tip).

In this study brittle fracture behaviour of a ferritic steel was predicted using a local approach and assessment procedure based on BS7910 [10] and R6 [11] for a pipe geometry. The local approach predicted $28 \%$ reduction in fracture load. Assessment codes based on FAD concept also predicted a $37 \%$ reduction in fracture load if the residual stress field was simply considered as membrane and bending stresses after linearisation. Linearisation method usually overestimates the residual stresses [10]. The reduction in fracture load was only $11 \%$ if the residual stress field were converted to secondary SIF using weight function using R-code [14] facilities.

This study does not include any experimental data from actual pipe to evaluate these predictions. Nevertheless, this study indicates that the local approach alongside assessment codes could be used to understand the interaction of residual stress with primary load more closely at crack tip to predict the brittle fracture. Moreover the intrinsic scatter in transition fracture toughness of ferritic material can be taken into account in the local approach method. Bear in mind that the prediction of failure based on local approach depends only on the evolving stress field during loading to fracture and any microstructural change due to load history has not been explored in this and previous studies. There are also different methods of considering plasticity effect ( $\rho$ factor) in assessment code which can significantly affect the failure prediction [26].

\section{ACKNOWLEDGMENTS}

The authors would like to thank Dr. S Smith from TWI Ltd for his valuable comments on this work.

\section{REFERENCES}

[1] Smith, D.J., (2003) "Comprehensive structural Integrity," 7.08, pp.289-347, Edited by Ainsworth, R.A., Schwalbe, K. -H., Elsevier Ltd.

[2] Kordisch, H., Boschen, R., Blauel, J.G., Schmitt, W. and Nagel, G.., (2000) "Experimental and numerical investigations of the warm-prestressing (WPS) effect considering different load paths" Nuclear Eng. \& Design, 198, pp.89-96.

[3] Lefevre, W., Barbier, G., Masson, R. and Rousselier, G., (2002), "A modified Beremin model to simulate the warm pre-stress effect," Nuclear Eng. \& Design, 216, pp.27-42,

[4] Margolin B Z, Kostylev V I, Keim E, (2004) "Prediction of brittle fracture of RPV steels under complex loading on the basis of a local probabilistic approach", Int. J Pressure Vessels and Piping, 81, pp. 949-959.

[5] Hadidi-Moud, S., Mirzaee-Sisan, A., Truman, C.E., and Smith, D.J., (2004), "A local approach to cleavage fracture in ferritic steels following warm pre-stressing," Fatigue Fract. Engng. Mater. Struct., 27, pp.931-942.

[6] Bordet, S. R., Karstensen, A. D., Knowles, D. M., and Wiesner, C. S., (2005) "A new statistical local criterion for cleavage fracture in steel. Part I: model presentation", Engineering Fracture Mechanics, 72, pp 435-452.

[7] Mahmoudi, A. H., Hadidi-Moud, S., Truman, C. E. and Smith, D. J., (2003) "A numerical and experimental investigation into the generation of residual stress in fracture specimens using local compression" ECF-15, Stockholm, Sweden.

[8] Mirzaee-Sisan, A., Mahmoudi, A. H., Truman, C. E., and Smith, D.J., "Application of the local approach to predict load history effects in ferritic steels", Proceedings of PVP2005: ASME Pressure Vessels and Piping Division Conference, July 17-21, 2005, Denver, Colorado, PVP2005-71606.

[9] Mirzaee-Sisan, A., (2005), "The influence of prior thermal and mechanical loading on fracture", $\mathrm{PhD}$ thesis, University of Bristol, UK.

[10] BS 7910, (2005), "Guide on methods for assessing the acceptability of flaws in metallic structures", BSI.

[11] R6, (2001), "Assessment of the Integrity of Structures Containing Defects", Revision 4, British Energy Ltd. 
[12] Hibbit, Karlsson and Sorenson Inc., (2003) ABAQUS Users Manuals, HKS Inc., 1080 Main Street, Pawtucket, RI 02680-4847, USA

[13] Crackwise, (2007), "Software of fracture and fatigue assessment procedures (BS7910) for engineering critical assessment", TWI Ltd

[14] R-code (2006), "Software for assessing the integrity of structures containing defects", British Energy Ltd.

[15] Beremin, F.M., (1983), "A local criterion for cleavage fracture of a nuclear pressure vessel steel," J. Metall. Trans. 14A, pp. 2277-2287.

[16] Pineau, A., (2003), "Comprehensive structural Integrity,” 7.05, pp.177-225, Edited by Ainsworth, R.A., Schwalbe, K. -H., Elsevier Ltd.

[17] Minami, F., Bruckner-Foit, A., Munz, D., Trolldenier, (1992) "Estimation procedure for the use of the Weibull parameters used in the local approach," Int.J.Fract. 54, pp. 197-210.

[18] Gao, X., Ruggieri, C., and Dodds, R.H., (1998), "Calibration of Weibull stress parameters using fracture toughness data," Int. J. Fracture 92, pp.175-200.

[19] Wiesner, C.S. and Goldthorpe, M.R., (1996), "The effect of temperature and specimen geometry on the parameters of the local approach to cleavage fracture." Jornal de Physique IV, pp.295-304.

[20] Milella, P.P., and Bonora, N., (2000), "On the dependence of the Weibull exponent on geometry and loading conditions and its implications on the fracture toughness probability curve using a local criterion," Int. J. Fracture, 104, pp.71-87.

[21] Petti, J.P. and Dodds, R.H. JR. (2005), "Calibration of the Weibull stress scale parameter, $\sigma_{\mathrm{u}}$, using the Master Curve", Engineering Fracture Mechanics, 72 pp. 91120.

[22] ASTM E1921 (2002), "Test method for the determination of reference temperature $T_{0}$ for ferritic steels in the transition range", Annual Book of ASTM Standards, 03.01.

[23] Bouchard, J. and Bradford, C., "Validated Axial Residual Stress Profiles for Fracture Assessment of Austenitic Stainless Steel Pipe Girth Welds" In proceedings of ASME Pressure Vessel and Piping conference (PVP2001), Vol. 423, pp 93-100: Fracture and Fitness, Atlanta, USA, 2001

[24] Hadley, I., Goldthorpe, M., Wei, L, (2006) "Complilation of $\mathrm{K}$-solutions for fitness-for-service procedures" Internal TWI CRP report, 849/2006.

[25] Khalili, A. and Kromp K., (1991) "Statistical properties of Weibull estimators,” J. Mat. Sci, 26, pp. 6741-6752.

[26] Mirzaee-Sisan, A., Truman, C.E., Smith D.J. and. Smith, M.C, "Interaction of residual stress with mechanical loading in a ferritic steel", Engineering Fracture Mechanics, In Press. 